\title{
RÉGION DU SUD-EST
}

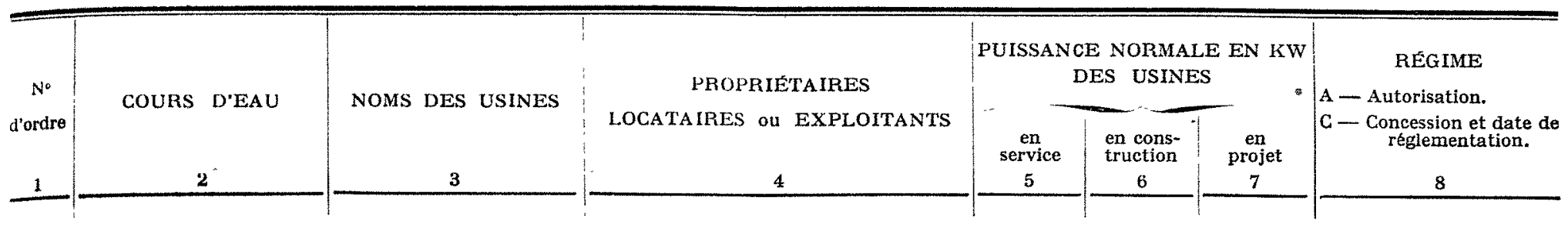

BASSIN DES DRAINCES

101 Drance d'Abondance Bonnevaux......... Société d'Electricité du Chablais,

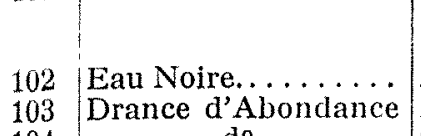

104

105 do

do

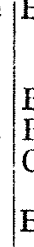
Thonon (Société des produits Société Electrique djênian-Tho non-Annemasse à Thonon.....

chimiques Coignet, à Lyon).... 3.300

650

\section{BASSIN DE IARVE}

\section{7 \\ 108

110 \\ 111 \\ 113 \\ 114 \\ 110 \\ 118 \\ 11 \\ 120 \\ 121 \\ 122 \\ 12 \\ 124 \\ 125}

126
127

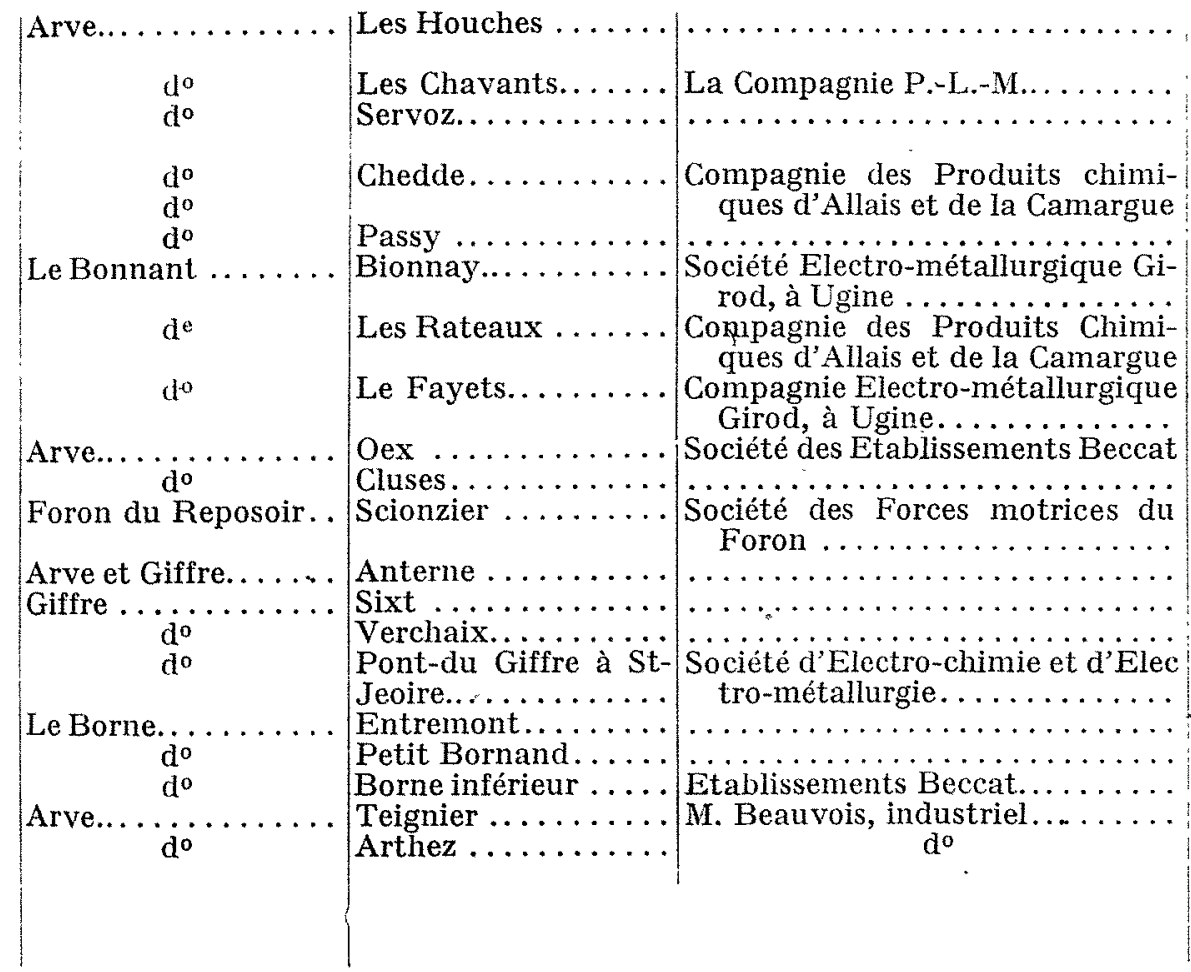

18

13

$\mid \begin{gathered}\text { Rhône } \ldots \ldots \ldots \ldots \\ \mathrm{d}^{\mathrm{o}} \\ \mathrm{d}^{\circ} \\ \end{gathered}$

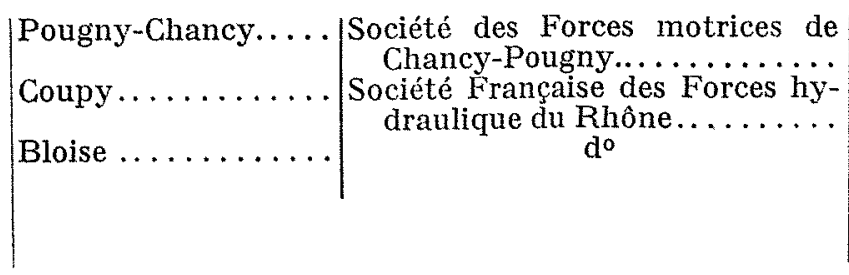

2.300

1.800

4.900

1.200

2.200

4.600

300

4.600

(

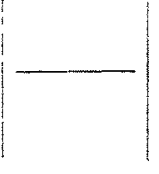

3.000

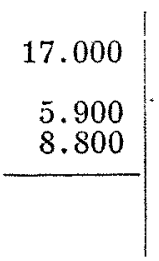

1.500

A -6 mars 1896 .

A -24 juilet 1907 ,

4 avril 1913 .

A - 20 février 1923.

2.800

A - 9 juin 1909.

A - 15 décembre 19

17.500

A - 5 avril 1902.

5.200

$\left.2.600\right|^{\mathrm{A}-15 \text { avril } 1907 .}$

5.900

5.700

A -17 juin 1899 ,

2.000

2.600

3.300

2.480

En instruction.

\section{BASSIN DE IA VAISERINE}

Valserine... $\mathrm{d}^{\mathrm{o}}$

do do
Usine de Niaiset..... M. Vallet, à Bourg
Usine de Sous-Roche

Sous-Roche

Compagnie du Chemin de fer d'intérêt local de Bellegarde à

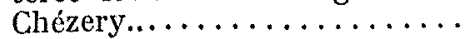

Moulin des Pierres... M. Gramont............. Bellegarde.

M. de Chanteau.............

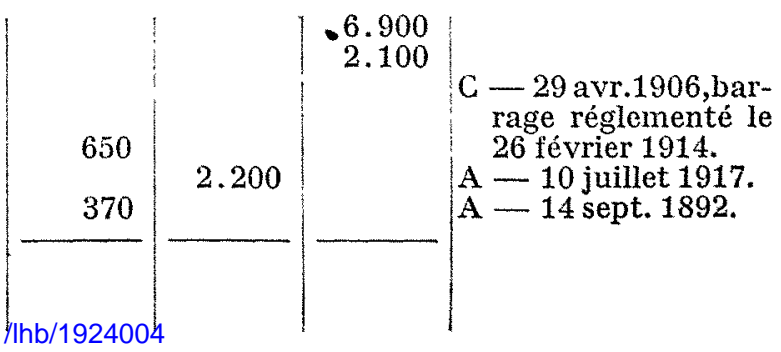

C - 20 mars 1919 .

A - 31 mai 1871.

C -27 décemb. 1918 


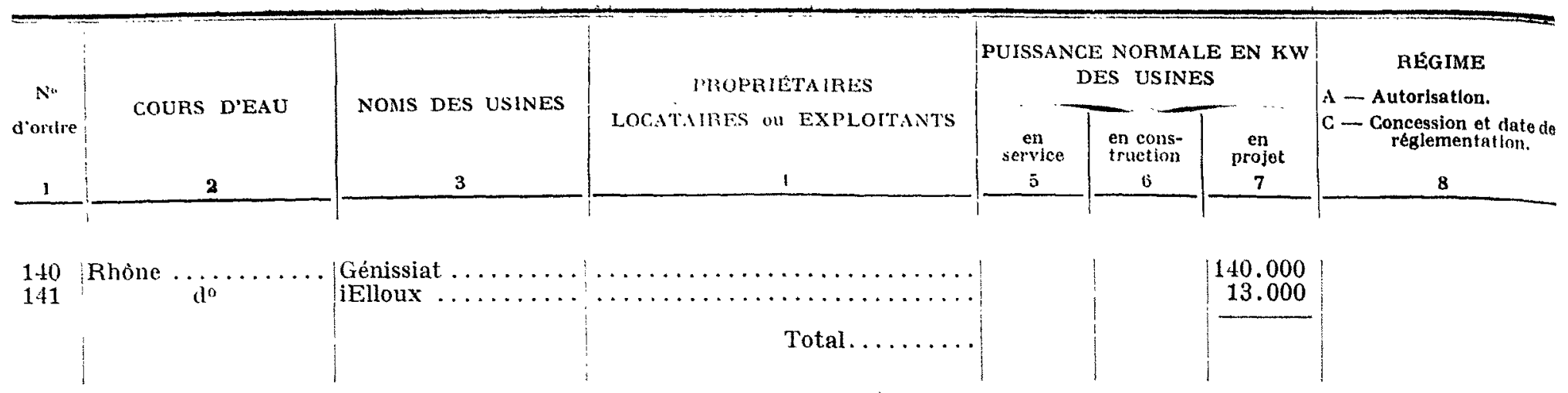

BASSIN DU FIER

143 Thiou ...

144

145

146

147
' Cran

Cran-Gévrier Brassily

Chavaroche ..........

Val de Fier......... Société Hydro-Electrique de Lyon 31 , rue Ferrandière, à I yon... .

Société des Fonderies et Forges

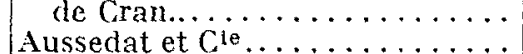
Société des Forces du Fièr, à Äncey $\ldots \ldots \ldots \ldots \ldots \ldots \ldots$ $\mathrm{d}^{\mathrm{o}}$ $\mathrm{d}^{\circ}$$$
\text { ; }
$$

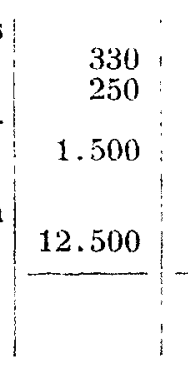

Mat

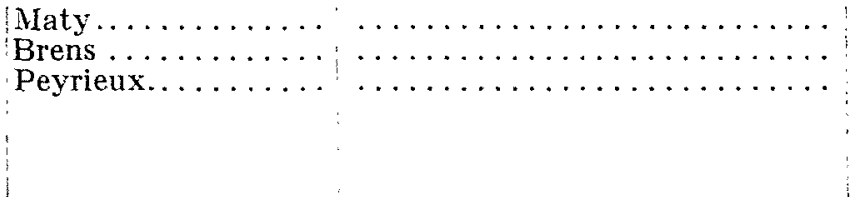

BASSIN DU GUIERS

153

$15 \cdot 4$

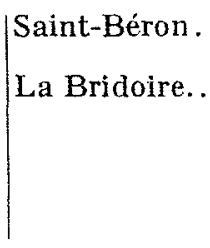

$\mid \begin{aligned} & \text { Saint-Béron } \\ & \text { La Bridoire. }\end{aligned}$

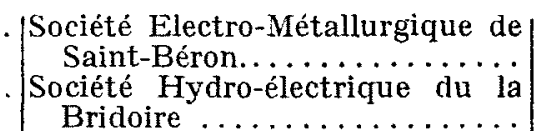

Bridoire

\section{BASSIIV DE IAIN}

158

159

160

161

62

163

$16 t$

165

166

167

168

169

170

171

172

$17: 3$
Bourg du Sirod..... Sté des Forces de Franche-Comté. Chalain........... L'Union électrique........... Lac deChalain............. Reau de Dombief, Lacde ma Motte, du Petit Macbu, Lac du Grand-Nacbu... La Motte. Le Durlon, Val-Chambly, Le Hérisson,

La Sirène ........ Chambly. .

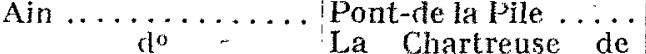

Vaucluse...........

Sociéte Industrie et Force......... Oignin.......... Trablettes . . . . . . Société des Forces de l'Oignin....

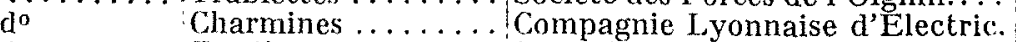
do Ferrières ........... Sociéte des Forces de l'Oignin...

$d^{o} \quad$ Izernore $\ldots \ldots \ldots \ldots$ $\mathrm{d}^{\circ}$

Ain $\ldots . . .$.

........................................

Cize-Bolozon ....... Société Rhòne et Jura ..........

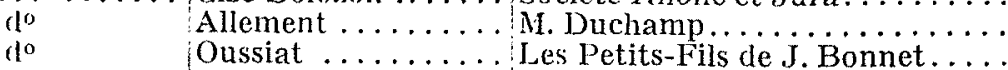

do Priay................ Vum.llermoz et Tézenas du

do

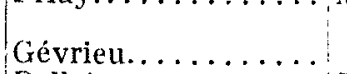
Montcel................ $d^{0}$ Montcel.............

Syndicat pour l'aménagement de

.

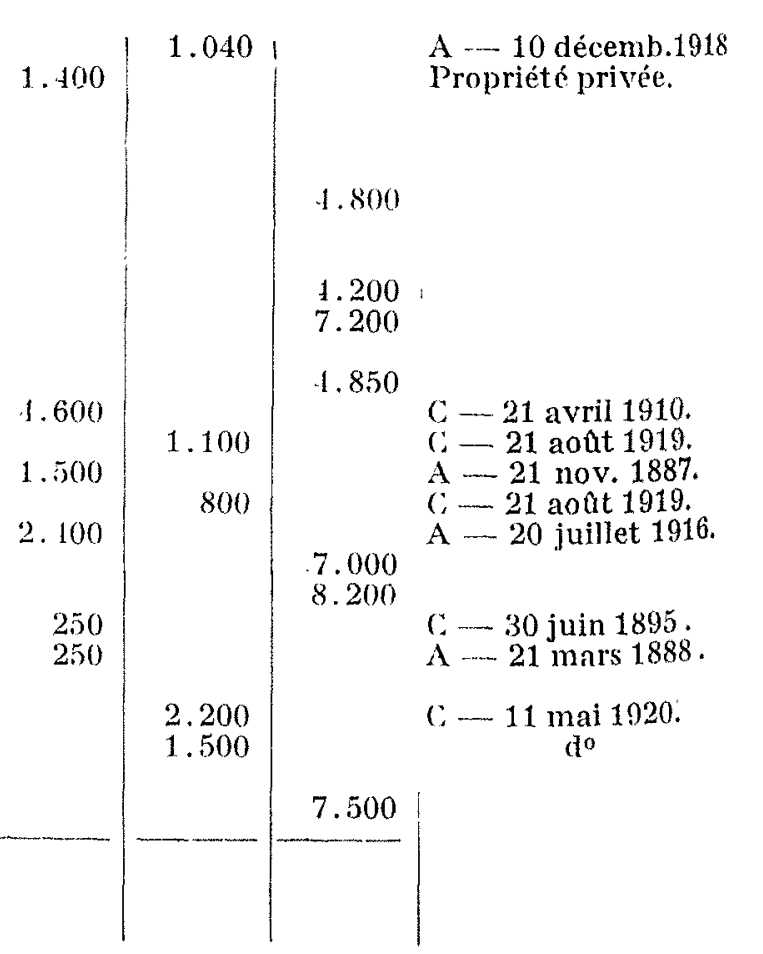

Concession du Gou. vern. Sarde.

Décret du $70 \mathrm{ct} .1843$

A - 23 juin 1897.

A -26 juin 1918

C - 21 aont 1913 .

A -- - 9 juin 1923.

A -8 juillet 1909 .

20.000

17.000 


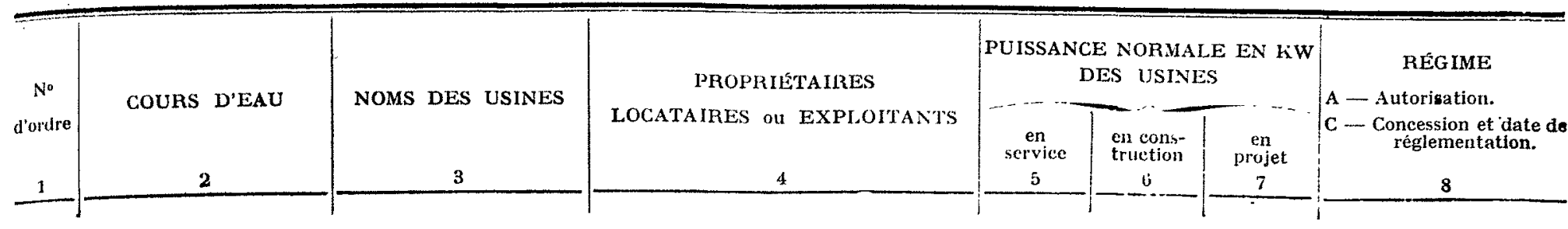

Rhône $\ldots \ldots \ldots \ldots \mid \begin{aligned} & \text { Villette } \\ & \text { Cusset. }\end{aligned}$

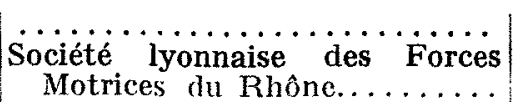
11.800
25.000

C -9 juillet 1892.

\section{BASEIN DU DOUPS}

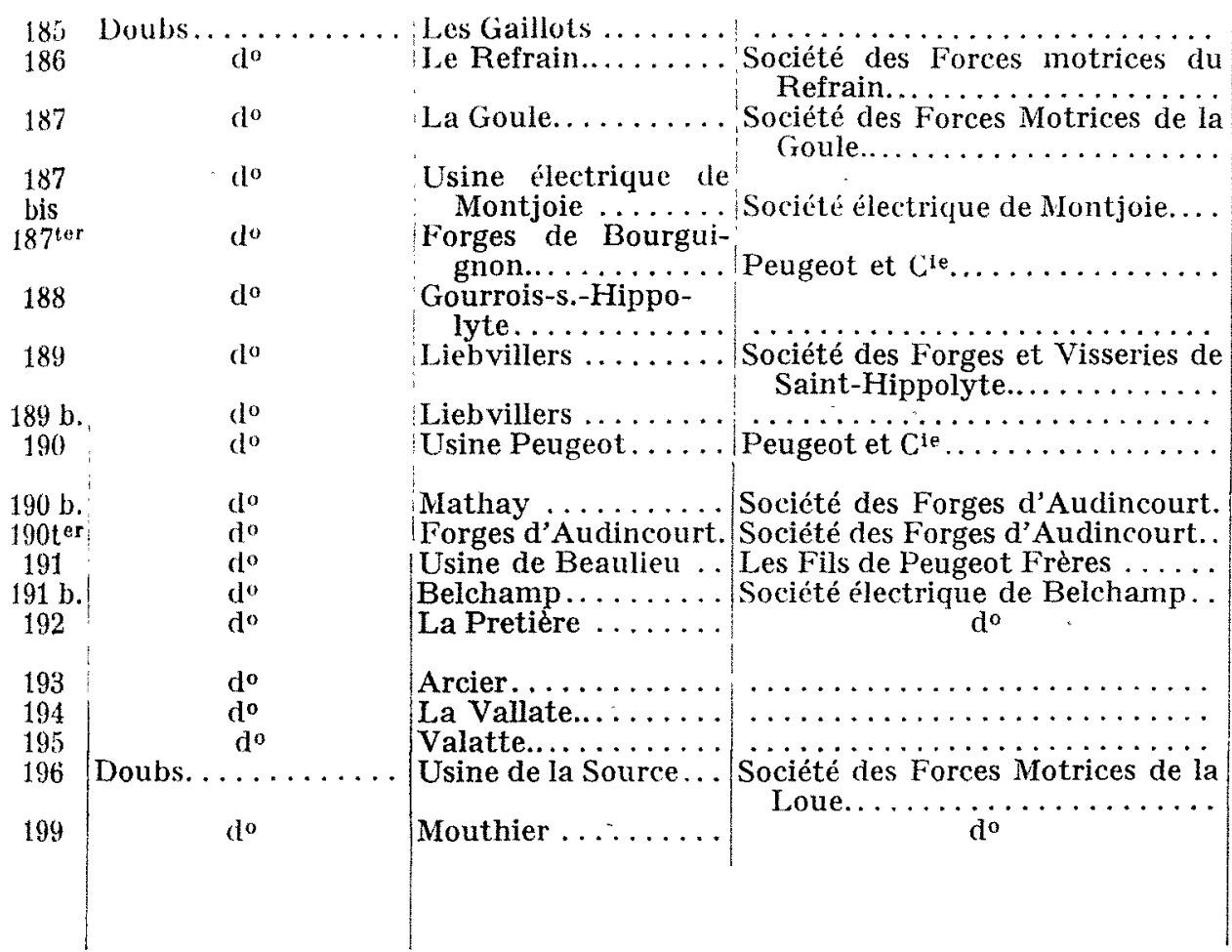

$\begin{array}{r}9.940 \\ 4.680 \\ 450 \\ 280 \\ \\ 850 \\ 1.200 \\ 520 \\ 600 \\ 280 \\ 370 \\ 1.250 \\ \\ \\ 780 \\ 5.040 \\ \hline\end{array}$

Ternay

Sainte-Colo..................

Sale

Saint-Rambert......

Saint-Vallier........

$\ldots \ldots \ldots \ldots \ldots \ldots \ldots \ldots \ldots \ldots \ldots$

Tournon.............

n.m.

Société des Forces Motrices du

La Roche-de-Glun..

forces Motrices du

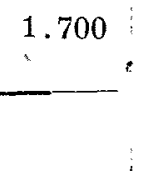

26.000

A - 8 janvier 1907 .

A - 20 juin 1898.

Non réglementéc.

A - 22 mars 1854.

8.400

A - 25 juillet 1846 .

2.200

A -17 juin $1853^{\circ} \mathrm{et}$

17 mai 1854.

A -29 nov. 1916.

A -28 mars 1857 .

A - 14 déc. 1884 .

A - 28 mars 1857 .

Demande de conces-

1.000

2.000

1.000

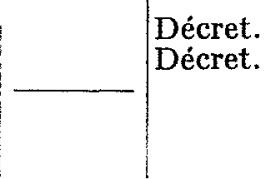

$\begin{aligned} & 19.500 \\ & 12.000 \\ & 42.000 \\ & 15.000 \\ & 21.000 \\ & 21.000\end{aligned} \mid$

BASSIN DE IIISHEF

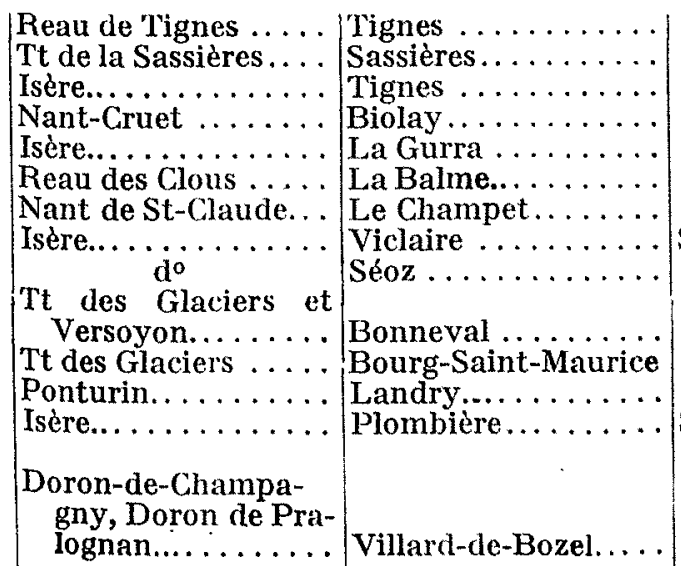

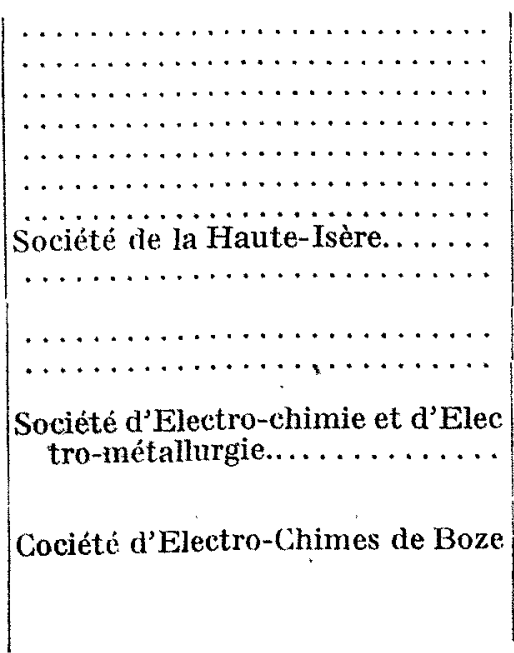

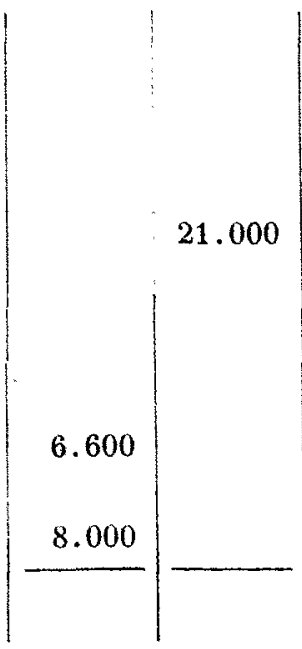

1.200

1.750

2.700

1.500

4.000

3.300

4.500

4.700

6.900

3.200

8.000

A - 22 avril 1899.

A -18 mai 1909 , 28 janvier 1899 . 


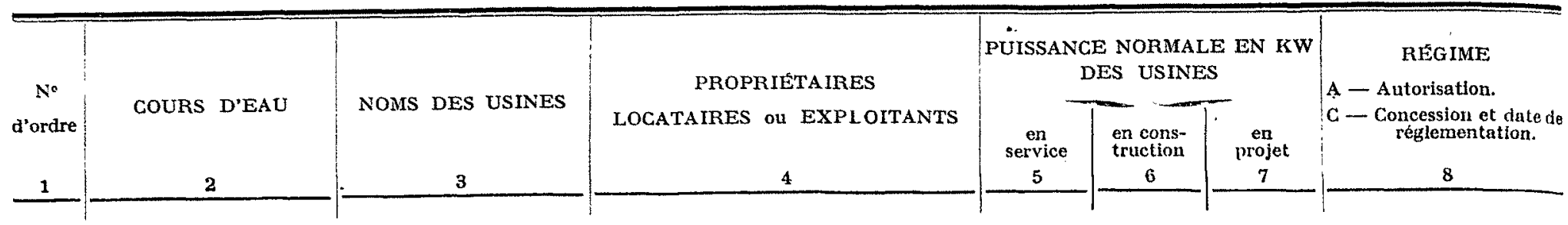

BASSIN DE L'ISERE (suite)

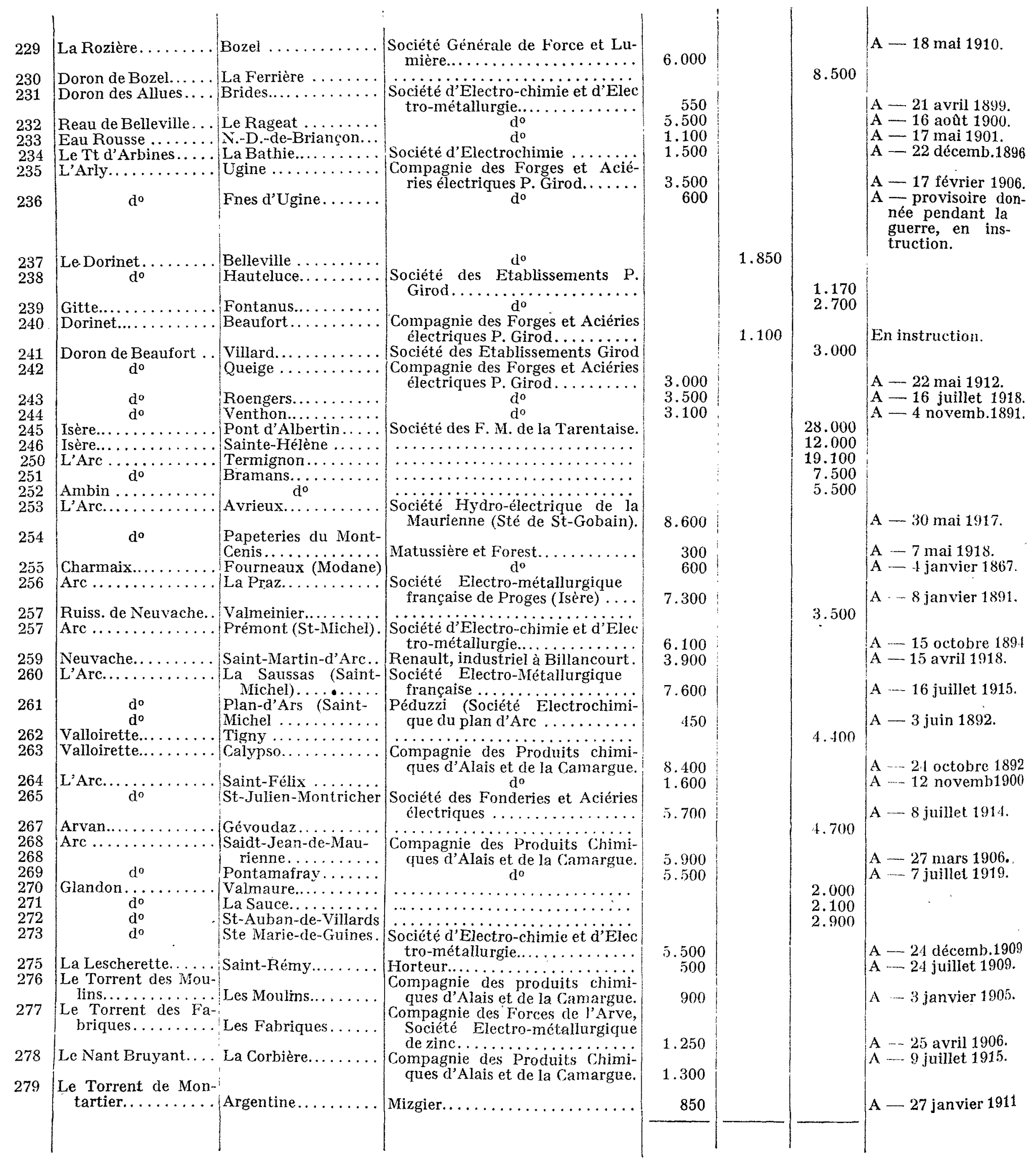




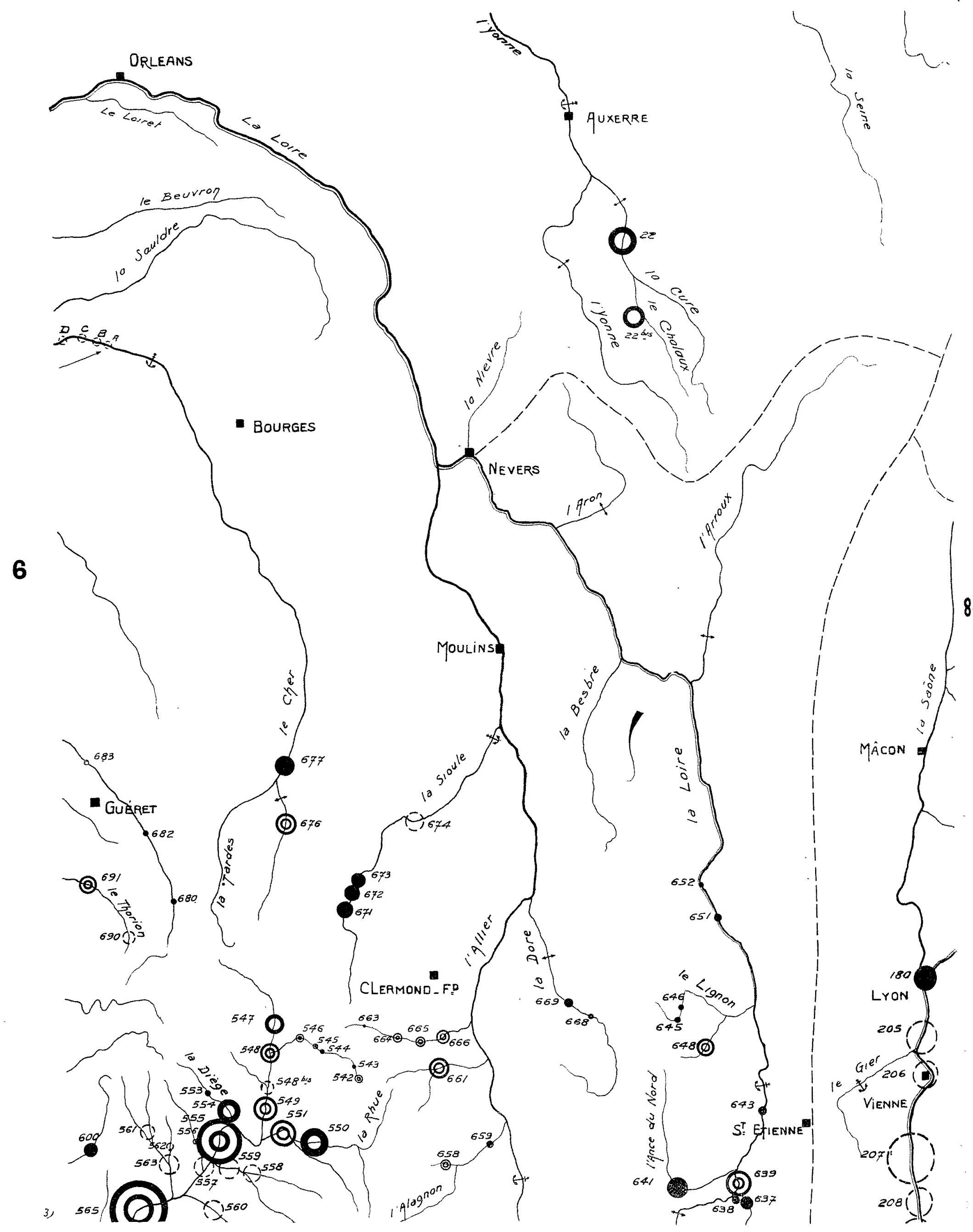




\section{4}

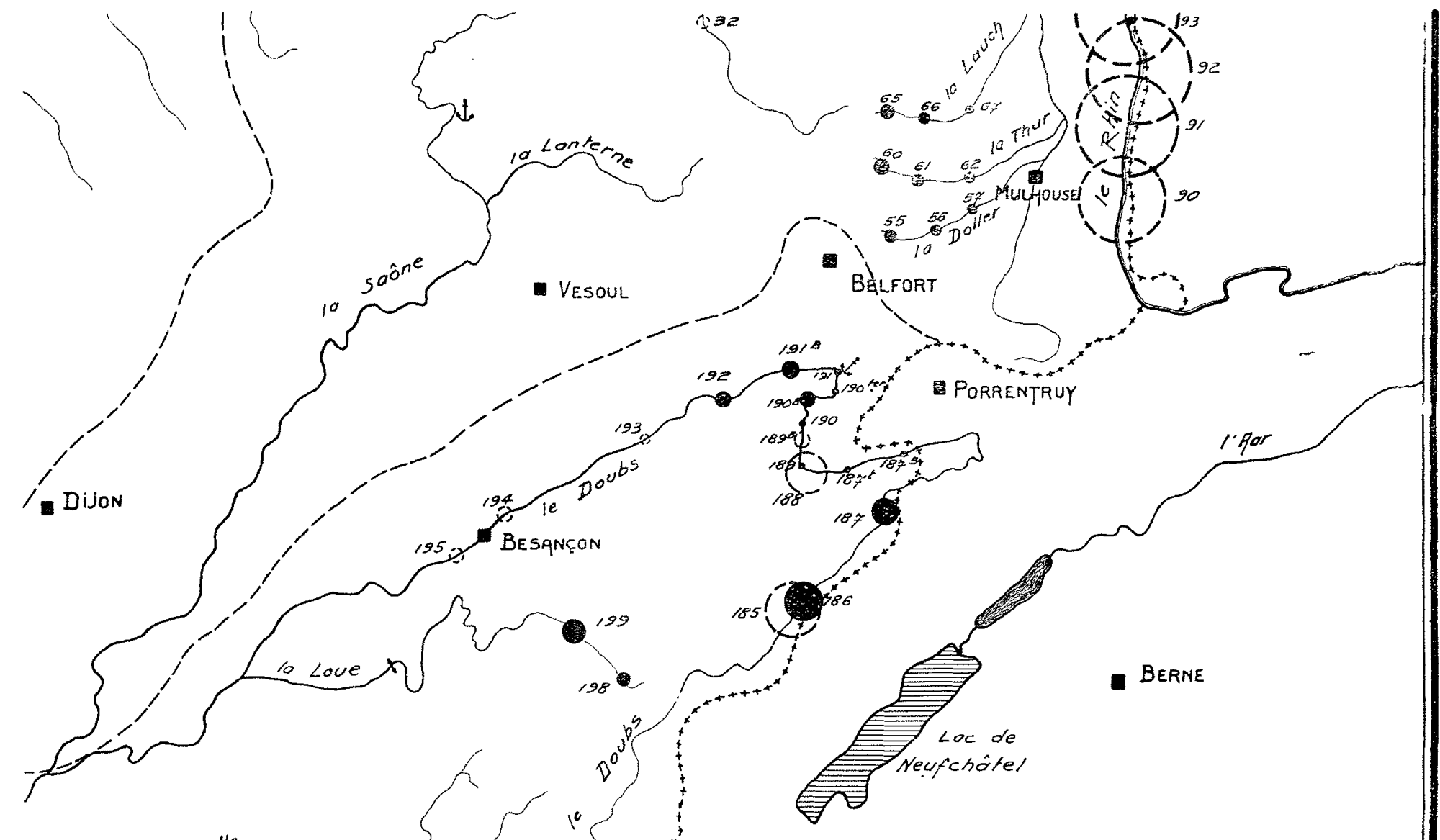

7

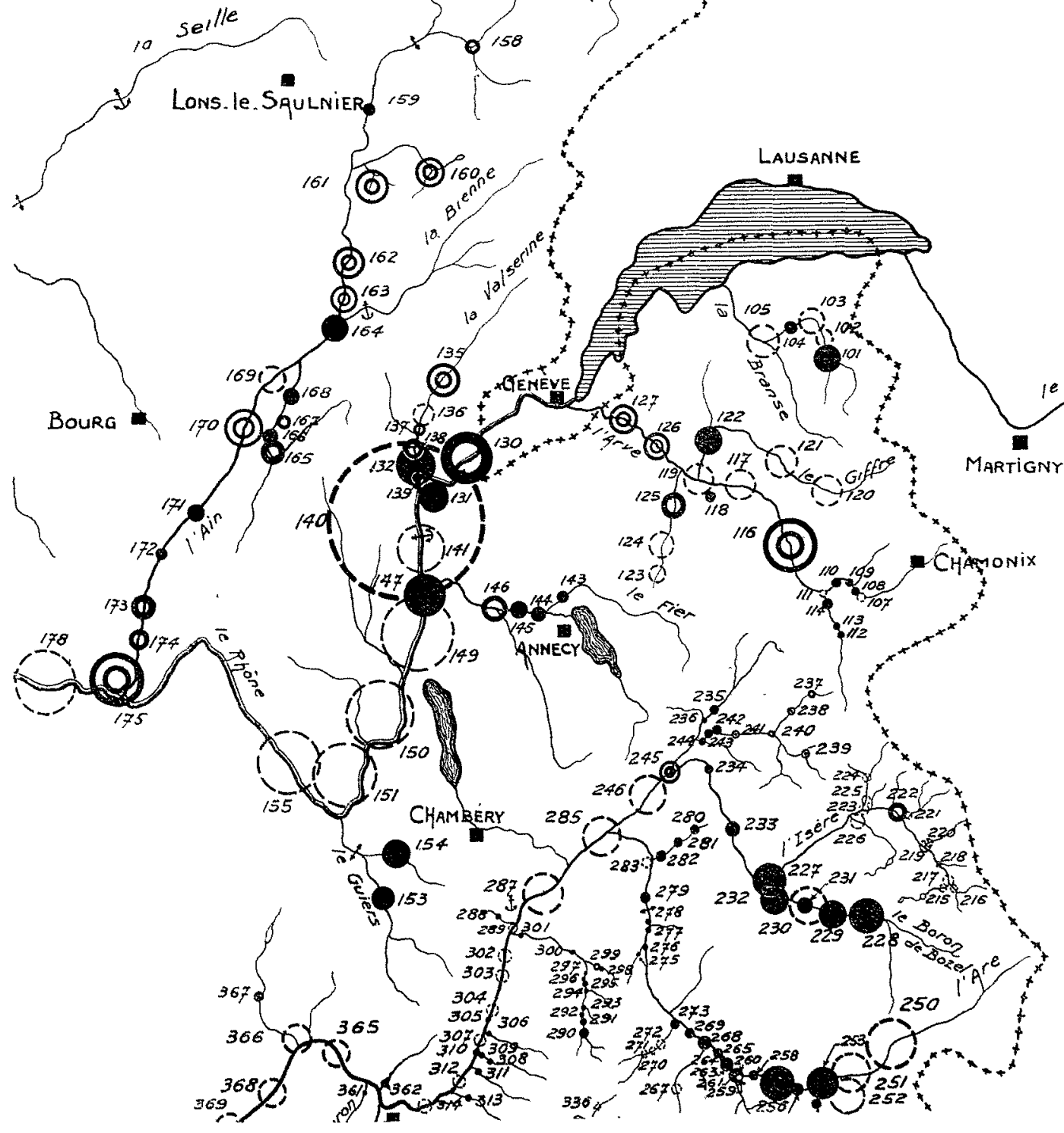

